\title{
Por uma política do co-passionamento: comunidade e corporeidade no Modo Operativo AND
}

\author{
Fernanda Eugenio $\star$ \\ AND Lab (Centro de Investigação em Arte-Pensamento e Políticas da Convivência), Lisboa, Portugal
}

\section{Resumo}

\begin{abstract}
Através de uma conversa situada com a prática do commoning e as questões do comum e da comunidade, este texto procura re-visitar a trajetória de pesquisa e o campo de inquietações do Modo Operativo AND - uma investigação praticada e de aplicabilidade transversal, acerca das políticas da convivencia e dos funcionamentos do Acontecimento, que venho desdobrando desde 2005 numa interlocução entre o fazer etnográfico e outros campos (em particular o da dança/performance e, mais recentemente, o da psicologia). Apresenta-se aqui, ainda, a mais nova ferramenta-conceito formulada no âmbito desta investigação - o co-passionamento - explorando as consequências que tomam (e fazem) corpo através da sua frequentação.
\end{abstract}

Palavras-chave: Modo Operativo AND; comum; comunidade.

\section{Towards a politics of "co(m)passionment": community and corporeality in Modus Operandi AND}

\begin{abstract}
Through a situated conversation alongside the practice of commoning and the issues of the common and the community, this text re-visits the trajectory of research and the inherent concerns of Modus Operandi AND - a transversal and practice-based approach to the politics of togetherness and the operative modes of the Event that I've been investigating since 2005. MO_AND rests in the interchange between the ethnographical ways of doing I've been practicing as an anthropologist and procedures coming from other fields (mainly dance/performance and, most recently, psychology). The newest tool-concept formulated within the framework of this research, "co(m)passionment", is also presented here and the embodied consequences that may emerge out of its practice explored.
\end{abstract}

Keywords: Modus Operandi AND; common; community.

A compaixão ocupou e ocupa um lugar de certo modo periférico na cosmovisão ocidental moderna, possivelmente como corolário da operação de "cisão" pela qual emergiram os valores fundantes do modo operativo da modernidade: a laicidade, o cientificismo, a objetividade e, sobretudo, o racionalismo. Esta operação cuidou em atribuir um lugar garantido porém apartado, em termos de legitimidade discursiva, à religião nas suas mais diversas formas, e a restringir o alcance e a transversalidade daquelas que seriam as suas práticas. Sendo a compaixão uma delas, sua inteligibilidade e sensibilidade tenderam a ser englobadas (e reduzidas) às molduras do discurso religioso, sobretudo aquele de tradição judaico-cristã. Modulados pelos mecanismos religiosos do assistencialismo, da caridade e da tutela, o falar e o fazer da compaixão não raro restringiram-se à chave "culpa-desculpa". A compaixão, que poderia ser, muito mais vastamente, experimentada enquanto "sintonia forte" - um "sentir-com" que não para de abrir brechas para a sintonização entre estranhos, alheios e díspares -, tendeu, ao contrário, a exercer-se como parte de jogos de poder destinados a continuadamente separar sujeitos e sujeitados, distintos e dependentes. Assim, o lugar possível para o exercício da relação de "sintonia forte" da compaixão foi consecutivamente confiscado por uma lógica moralista, "educativa" e "salvadora" - lógica que salva sob a condição de colonizar; que consente em incluir sob a condição de civilizar; que enxerga o outro sob a condição de vê-lo

\footnotetext{
^Endereço para correspondência: AND Lab, Centro de Investigação em Arte-Pensamento e Políticas da Convivência. Travessa das Almas, 2, 2 ${ }^{\circ}$ Esq. - Estrela. Lisboa - Portugal. CEP: 1350-003.E-mail: info.andlab@gmail.com
}

faltante - e que atua por perpetuação da falta, de modo a permitir que um Eu hierarquicamente superior possa, em loop, exercer a sua bondade e expiar a sua culpa.

Isso diz muito sobre o funcionamento do Estado um Estado que, entre nós, se funda por invenção geminada com o individualismo (VIVEIROS DE CASTRO; ARAÚJO, 1977). Funda-se porque, em havendo um indivíduo que doravante desprende-se do coletivo para se apaixonar por si mesmo (sendo até o apaixonamento pelo outro um modo sobretudo de fazer identidade), este passa a desejar cuidar tão somente de si, abandonando a coisa pública e aquilo que poderia ser o comum, delegando o "entre-nós" a ser legislado a partir de fora por uma máquina de Estado. Ou seja, o mesmo movimento que reduz a compaixão a um gesto compulsório (para o crente) e dispensável (para o indivíduo moderno) é o que faz da paixão um gesto fundamental para a identitarização do eu. E ambos estes gestos, juntos, operam a indiferença como modo de estar em coletivo, confiscando-nos uma imensa força vital que poderia ser força de "autogoverno" e de gestão coletiva dos nossos acontecimentos comuns. Força relacional que, por vitalismo e propagação, já tenderia a priorizar inevitavelmente o comum e o acontecimento, a operar em "modo default" por simpatia e solidariedade. A força do "passionamento" que só poderia, não fosse o instaurar da cisão moderna, ser "co-passionamento".

A pesquisa do Modo Operativo AND vem se dedicando a perceber sensivelmente como operar, no corpo do dia-a-dia, práticas na direção de uma 
“des-cisão": ${ }^{1}$ de um desfazer da cisão moderna através de modos de entrar em relação que permitam reencontrar, nas nossas "decisões" mais cotidianas, um "inter-isso" enquanto afetação recíproca e situada. "Inter-isso", questão entre-nós, inquietação do juntos, capaz de, ao mesmo tempo, não se confundir com o mero "interesse" e fazer frente ao "inteiriço" compacto da indiferença (ou da identidade), para encontrar a cada vez a multiplicidade do "inteiro" que é o comum. Comum enquanto diferença conseqüente da relação. Relação que é viva enquanto segue diferindo, "des-cindindo" e "dissentindo". Frequentar o Modo Operativo AND convoca, assim, a revolver os modos pelos quais a compaixão foi social e politicamente confinada dentro de um quadro moral, reencontrando-a, enquanto ética de cuidado situado, enquanto força de moção comum - "co-moção". A proposta, com o Modo Operativo AND, é estudar e praticar meios possíveis para sintonizar o "co-passionamento" enquanto potência de vínculo entre diferentes, capaz, quem sabe, de prescindir tanto do gesto normativizador da identificação e da identitarização, quanto do gesto normalizador da compassividade e da complacência.

É nesta "altura" - aqui tomada simultaneamente como espaço e tempo - que gostaria de propor um encontro entre o Modo Operativo AND e as ferramentas conceituais desdobradas no plano dos estudos e reflexões sobre comunidade e corporeidade.

\section{O Modo Operativo AND: nem supor, nem impor; compor, com-pôr, pôr com}

$\mathrm{O}$ funcionamento social dominante ou encompassador no mundo em que vivemos - não necessariamente por ser maior do que nós, mas por ser reiteradamente ativado à nossa escala - é o de assumir a existência prévia do ideal, ou da ideia, ou do modelo, qualquer coisa que legisla o que é ou deve ser o "jogo da vida", por pré-determinação

\footnotetext{
"A noção de "Des-cisão" - em relação de triangulação com "cisão e decisão" - é parte do conjunto de ferramentas-conceito AND, que venho desdobrando na pesquisa da etnografia enquanto performance situada do encontro, ou Modo Operativo AND, a partir de um esforço de exploração da plasticidade das palavras para fazê-las dizer e performar outros mundos possíveis. São também ferramentas-conceito AND, muitas das quais serão mencionadas ao longo deste texto: o "re-parar" (parte da tripla modulação "parar", "re-parar" e "reparar" síntese do Modo Operativo AND enquanto trabalho de "reparagem" ou treino de "desfragmentação"); a "re-existência" (em tensão com "existência", "desistência" e "resistência"); a "posição-com" (em tensão com "composição" e "imposição"); além do neologismo "secalharidade" (em tensão com a "modernidade" e a "pós-modernidade"); a formulação dos Modos Operativos É-OU-E, o jogo das perguntas QUE-COMO-QUANDO-ONDE; o jogo de descrição-circunscrição/formulação-performação ISTO-ISSO-ISTO; o Diagrama de Posicionamento Aberto-Explícito (em continuum com as zonas extremas do "implícito" e do "fechado") e as duplas saber/"sabor", coerência/"consistência", eficiência/"suficiência", explicação/"implicação", representação/"presentação", relevância/"relevo", rigidez/"rigor", justiça/"“justeza", fragmento/"fractal”, (in)dependência/"“autonomia" etc. Para outros textos nos quais estas ferramentas são exploradas em mais detalhe, Eugenio (2010, 2012, 2017), Eugenio e Fiadeiro (2013) e Duenha, Eugenio e Dinger (2016). Fazer (com) conceitos, tornando-os em ferramentas para a tomada de posição através de dispositivos de jogo performativo, tem sido a tônica de minha trajetória de pesquisa, primeiro estritamente no campo da antropologia, a seguir numa interlocução com o campo das artes performativas e da presença. Este trabalho continuado adotou diferentes nomenclaturas desde 2005 (Sistema É-Ou-E e Modo de Vida E, entre 2005 e 2006; Etnografia Recíproca e Etnografia como Performance Situada, mais fortes entre 2006 e 2008, mas ainda hoje utilizadas; Re-programa, Reparagem e Pensação, mais fortes entre 2009 e 2011, mas ainda hoje utilizadas), até ser sintetizado no formato hoje conhecido como Modo Operativo AND - síntese para a qual foi de grande importância o período de colaboração intensiva com o coreógrafo português João Fiadeiro (2011-2013), no âmbito do qual o AND Lab foi fundado em Lisboa.
}

de um conjunto de decisões entre certo e errado, bom e mau, justo e injusto, animado e inanimado, humano e não-humano, homem e mulher, homens e animais, adultos e crianças, normal e patológico, opressores e oprimidos, objetos e sujeitos, sujeitos e sujeitados etc. Assume-se que este mapa de oposições binárias e duras seria apenas um modo de dizer a verdade de uma essência ou substância que preexistiria às relações, e daria o corpo dos entes e dos termos. Neste sistema, trabalha-se por cancelar o desconhecido e o inesperado, por controlá-los tornando-os previsíveis, enfeixando-os num conjunto de cisões que, doravante, passam a servir de modelo: todos os movimentos que acontecem passam, assim, a ser precedidos pela sua autorização, por um saber que já os decifra de antemão e já prescreve a conduta apropriada. A tendência deste funcionamento é a de consecutivamente dar lugar à reprodução e à representação. E estas só se interrompem quando colidem com um acidente de proporções tais que inviabilizam esta (pós-)moderna "mobilização infinita" (SLOTERDIJK, 2000) de avançar com o saber, dando notícias do (até então) impossível e impensável. Não há recursos, neste sistema, para se lidar com o acidente 'inanexável' à lógica da explicação, da interpretação, da atribuição de valências e sentidos que esquadrinham, regulam e hierarquizam - a lógica do saber. Daí que, quando eles acontecem, o sistema paralise, traumatize.

A não ser que tenha havido também o treino da atenção e da sensibilidade para outras faixas de frequência - aquelas que operam no intervalo, "entre" e "ao longo" das linhas do encontro: no E. E isto porque, à revelia da pretensão de controle totalitário das diversas variações do Modo Operativo É que regulam de modo mais ou menos espraiado, contemporaneamente, o socius global, há sempre, na multiplicidade dos encontros, um outro modo operativo a fazer vida constantemente na surdina: o Modo Operativo E (AND). Porque os eventos estão sempre a incidir aquém ou além das prescrições e regulações; daquilo que supõe ou impõe o funcionamento É: no limite, não há outra coisa senão acidentes. O Modo Operativo É até pode desejar a (e trabalhar pela) supressão de tudo o que escapa aos seus moldes, mas não sendo esta de fato possível - é da "diferencialidade da diferença" como processo vital que o funcionamento E dá notícias, microscopicamente, a cada vez -, o que o sistema É acaba por fazer mais eficazmente é assegurar a nossa insensibilização (ou imunização, como veremos mais adiante) a este murmúrio de acidente-e-improviso, tentativa-e-erro, que vai sendo a matéria e fazendo a consistência das nossas relações nos mais variados planos, dos mais infinitesimais, diminutos ou íntimos aos mais alargados, mundiais, cósmicos, num fazer constante e invisível de "re-mediação": de "des-cisão" das proclamadas cisões (ou oposições binárias) modernas.

Daí que o trabalho a fazer, para desviar do É sistêmico - e da sua impossibilidade congênita de acolher o acidente - não seja negá-lo ou confrontá-lo, mas, sobretudo, consista num sintonizar com a faixa de frequência menos ruidosa do E, que está sempre lá. Trabalho de sensibilização e fractalização da atenção: esforço por distribuí-la na 
multidirecionalidade sem significado do acontecimento, por distrair-se das intencionalidades do "Eu" através da "co-operação" com o desdobrar das relações. Fazer da atenção um gesto de cuidado e sustentação daquilo que se vai (re)conhecendo conforme se vai deixando de saber: o alinhamento intensivo dos corpos e dos afetos, ao longo dos quais a malha da vida se tece ilimitadamente.

Este cuidado enquanto "atenção distributiva" permite prescindir tanto da suposição quanto da imposição, abrindo brecha para que a tomada de posição se faça, a cada vez, com a matéria da posição que já lá está, se manifestando enquanto "com-posição" - ou, ainda mais precisamente, "posição-com". Um lidar situadamente com os problemas; um diluir dos contornos do "problema meu" no "problema situado". Frequentar o Modo Operativo AND envolve, por isso, conter o automatismo do saber, e a tentação reiterativa de ativar as regras de um jogo previamente estabelecido, para percorrer e mapear as condições que se apresentam, para manuseá-las e deixar-se manusear dando lugar ao encontro do jogo justo: aquele que se propiciar. Envolve desviar tanto do vitimismo quanto do controladorismo que poderiam levar a acatar enquanto "condicionantes" as "condições" de possibilidade que suportam o encontro - e envolve, sobretudo, fazê-lo sem, entretanto, confundir esta disponibilidade de aceitação, não-julgamento e reconhecimento que habilitam para a luta ("lutar é fazer com o que se tem") com a resignação, o conformismo ou a desistência que resultam do entrincheiramento no juízo e na opinião. Por fim, envolve ainda trabalhar para que o mapa (o mapa do que há, e do que este possibilita) se desdobre reciprocamente, atmosfericamente, "des-cindindo" as fronteiras entre sujeito e objeto, eu e entorno, para disseminar o olhar em "reparagem" filigranar: aquela que fará de tudo - meu, teu, delu(s) ou nosso - matéria de commoning (STAVRIDES, 2016) e emaranhado de vida.

\section{A sensibilidade etnográfica e a prática do co- passionamento: sintonia, commoning e strangership}

O Modo Operativo AND emerge, inicialmente, das questões que cercam o encontro etnográfico e da oportunidade de invenção recíproca que este porta consigo. Esta oportunidade, sendo inerente à situação-encontro, não é inerente a toda e qualquer forma de praticar a etnografia; algumas delas, ao contrário, podem se construir justamente a partir do seu cancelamento sistemático pela via da interpretação e da produção de diagnóstico sobre o outro. O Modo Operativo AND, portanto, frequenta uma modulação singular da etnografia - aquela que se compromete de modo radical com a sustentação do não-saber, com o trabalho pela re-materialização do possível, do pensável e do praticável através da afinação sintônica com a "força-questão" e/ou a "forma-problema" performada(s) no encontro com o outro. Trata-se de um trabalho com a matéria daquilo que se "desobvia" quando reconhecemos e nos dispomos a habitar um território “alterotópico" (PETCOU; PETRESCU, 2007): a matéria inominável do "Isso" (JULLIEN, 2000).

Fractal, Rev. Psicol., v. 29 - n. 2, p. 203-210, 2017
Tocar nesta matéria inefável, dizê-la consecutivamente ao mesmo tempo em que se trabalha por preservá-la indizível, é uma possibilidade que se mantém viva na medida da nossa capacidade de fazer do encontro um encontro sustentado, dando espaço para a emergência lenta e gradual de um plano comum descritivo e circunscritivo, "sem pressa de saber". Esta possibilidade "dá-se mas não é dada": é preciso trabalhar por ela, através da clarificação e da potenciação da dimensão "performativa" do encontro etnográfico, feita sobretudo de um esforço de sintonização com modos alheios de perguntar (e, com isso, de formular o acontecimento) - um trabalho de "correspondência", nos termos de Ingold (2012), ou de "co-passionamento", como o tenho formulado.

Esta dimensão da prática etnográfica não é aquela que se habita preferencialmente na prática antropológica de produção de conhecimento acadêmico. Sintonizar com ela foi, por isso, suscitando lentamente um campo de Fora - que colidiu num primeiro momento com o campo da dança e da performance e, nos anos mais recentes, tem feito Fora numa entrada em conversação com as práticas de mediação e clínica transdisciplinar da psicologia, com as práticas alterotópicas na arquitetura e no urbanismo, com as pedagogias radicais exploradas no campo da educação, com os estudos de informática dedicados à interação humano-computador etc.

O Modo Operativo AND, enquanto filosofia habitada, envolve um comprometimento por colocar no mesmo plano o pensar e o fazer, conjugando, por um lado um "esforço do formular" - gerar em ato o vocabulário justo para dizer os modos operativos do acontecimento - e, por outro lado, um "esforço do concretizar" - materializar a formulação em gesto e tomada de posição, efetuando os conceitos como ferramentas. A conjugação desses esforços - "dar palavra ao corpo e dar corpo à palavra", recursivamente - tem a ver com a possibilidade de ganhar intimidade infinitesimal com o fenômeno da relação e do relacionar-se, e em especial com o seu disparador: a afetação recíproca, o "co-passionamento". Habitar uma certa inflexão diminuta do pensamento investigativo, em que este se investe de franqueza, disponibilizando todos os seus recursos para acompanhar "de perto em perto", e com precisão, a própria imprecisão do viver junto - na sua incongruência e incoerência vivas, desviando o destino habitual dos conceitos de servirem para consertar e "coerentizar" a imprecisão, fazendo-os seguir, dizer e fazer a "malha" multidirecional e multicentrada da vida (INGOLD, 2012). Deixar de interpretar, em suma, para dar lugar a um "mapa trajetivo" (DELEUZE, 2000) que vai se desenhando conforme se assiste (no sentido de prestar assistência, não de "espectar") o encontro em seu desenrolar "indefinido" e "impessoal".

Este pensamento-em-ato do Modo Operativo AND que chamei de "pensação" - foi aos poucos vazando e transbordando do campo de problemas contra o qual se formulou (o campo da antropologia). Propagando-se de modo não planejado, assistemático e acidental, tem encontrado nos últimos anos outros e cada vez mais variados interlocutores e usos, assim ganhando corpo como pesquisa 
transversal dos modos de transmutação da "síndrome do dar-resposta" numa "força-tarefa de dar-pergunta". Foi se tornando numa ética - a "ética da suficiência" - e num modo de vida: o do fazer comunidade prescindindo do mecanismo identitário da pertença e da reprodução (seja pela filiação direta - kinship - ou, no máximo, por afinidade eletiva, friendship) para frequentar o mecanismo do impróprio e do comum - aquele disposto a fazer, a cada vez, strangership (HORGAN, 2012).

Ao sublinhar uma disposição por fazer no "dissenso" (RANCIÈRE, 2005) - ou seja, por, mais do que "falar com estranhos", "(dis)sentir com" eles, prescindindo da identificação como motor de solidariedade, e fazendo desta sobretudo um compromisso de afinação com o problema alheio por "frequentação" - dispomo-nos a explorar outras modulações da comunidade. Esta deixa de ser um fechar-se sobre si ou "os seus" para tornar-se numa disposição e num gesto: o do commoning, do fazer-com (potencialmente) qualquer um ou quaisquer muitos. Saímos, assim, da esfera de um pensamento entitário da comunidade, que tende a encará-la como substância partilhada de antemão (por sangue ou solo, por exemplo) ou como instância de respaldo à (re)afirmação identitária dos indivíduos, para adentrar num modo de formular e praticar a comunidade enquanto experiência sobretudo de "dessubjetivação coletiva" - e, portanto, como processo de "vinculação" sempre (em) aberto.

Ativar este outro modo de abordar e praticar a comunidade envolve sintonizar com um comum que não é nem essencial nem substancial, mas potência. Algo que já lá está, desde sempre, mas enquanto virtualidade a ser realizada, e não enquanto essência ou verdade original. É virtualmente possível virmos a ter um comum justamente porque somos irremediavelmente diferentes e outros: é do fato de que há distância entre nós que emerge a possibilidade de ligá-la, de maneiras ilimitadas, que estão sempre por inventar a cada vez. Se já estivéssemos próximos, se já fossemos o mesmo, não haveria nem hipótese nem necessidade de fazer comum: o comum não se manifesta, portanto, na identidade nem na identificação, mas na possibilidade de ligar os díspares, os discordantes, os diferentes. Mas, porque é possível, mas nem por isso garantido, "o comum custa", dá trabalho: o trabalho de "passar do comum (virtual) à comunidade (que se realiza)", da potência à posição, e da posição à com-posição, percorrendo "de perto em perto" as distâncias que nos juntam e separam ao mesmo tempo. A comunidade é, desta perspectiva, a consequência de uma "ética da composição”, como já sinalizara Deleuze (1981): o plano de consistência ou de imanência ao mesmo já está lá e precisa de ser composto, da mesma maneira que um corpo se define pelo que ele pode, mas não há como saber de antemão o que pode um corpo, sendo preciso equilibrar-se entre o risco e a prudência para, em relação, corporificar.

Esta "comunidade dos que não têm comunidade" (para usar a expressão torta, e por isso mesmo tão precisa, de BATAILLE, 1992) nada tem a ver com o igual, o homogêneo ou o consensual - formas nas quais a cosmovisão ocidental moderna procurou fazer caber o co- mum, esvaziando-o do seu caráter político para tentar fundi-lo ao "conceito fraco" da semelhança, ou fazer dele mero sinônimo de noções puramente lógicas, como a de "universal", ou eminentemente econômicas, como a da "igualdade/uniformidade" (JULLIEN, 2010). Entretanto, ao invés de assentar a sua manutenção num esforço por levantar trincheiras físicas e/ou imaginárias, na reivindicação de supostas purezas originárias, essências autênticas ou pertencimentos ditos mais legítimos do que outros, o comum faz-se possível, a cada vez, justamente na "impossibilidade da conciliação e da pacificação", e num esforço deliberado (e inevitavelmente político) por "fazer co-operar" diferenças em encaixes situados, provisórios, heterogêneos e desiguais.

"Fazer (n)o difícil", nas palavras de Nancy (2014) para descrever o trabalho minucioso e diligente da "escuta": e não seria numa escuta mútua que habitaria a hipótese de uma compreensão capaz de desviar da sinonímia privilegiada com o entendimento, para assentar sobretudo num dos seus sentidos menos empregados cotidianamente, mas eventualmente mais potente - o de compreensão como "abarcamento"? Sim, o comum envolve mesmo isto: ser capaz de "abarcar sem entender, considerar sem julgar, incluir sem classificar”. E isto porque não é possível associar o comum, senão abstratamente, a modelos tais como o de um fundo originário - uma dita natureza partilhada, sobre a qual teria se adicionado a roupagem da diferença, ideia-chave do relativismo cultural - ou o de uma síntese ou denominador comum, minima moralia ou "bom senso" - ideias-chave do pensamento universalista. Diante dos choques concretos e situados da convivência, nenhum desses dois recursos é suficiente para efetuar o encontro de modo justo, já que não se chega ao comum por média: "o comum não é meio termo, mas meio ambiente" - "justo meio", na expressão de Jullien (2000).

Não é possível fazer comum por "pressuposição", assentando-o na alegação de fundos (naturezas) ou superfícies (consensos); tampouco se pode fazer comum por "imposição", via pela qual se pode, quando muito, fabricar uniformidade por terraplanagem. Como diz Latour (2011), "não existe mundo comum; é preciso compô-lo": o fazer comum tem como caminho possível a "composição", e como modo operativo o transformar do gesto compositivo numa arte política da reciprocidade, num trabalho de "posição-com". "Tomar posição com a posição do que já lá está" envolve disposição para recomeçar a cada issue - a cada acidente e problema dele emergente -, pois "não há nada que possamos transportar tal e qual de uma situação a outra; a cada vez será preciso ajustar e não aplicar, descobrir e não deduzir, especificar e não normalizar, descrever - antes de tudo, descrever" (LATOUR, 2011, p. 40, tradução nossa). E, acrescentaria ainda: chegar, por esta via da descrição-manuseamento, à "circunscrição", à enunciação das relações-tensão que se cruzam e fazem a superfície de contato entre os problemas, este lugar-situação que "se dá" ao encontro, mas por si só não o garante: reconhecer e "aceitar" a sua matéria, 
inventariar o que ela pode e o que podemos nós com ela, tornando então o lugar-situação em lugar-comum, performando o "retribuir".

Valerá, assim, voltar a atenção à própria palavra comunidade para ver como se poderia fazê-la passar de conceito à ferramenta para este trabalho diminuto e situado, o de "posicionar-se com a posição do que se apresenta". Recuperando a etimologia da palavra latina communitas - contração dos radicais cum (o outro, o "além de mim") e munus (o dom, simultaneamente dádiva e dever) - Espósito (2007) faz um sensível trabalho de re-enunciação, que permite voltar a explicitar a operação de reciprocidade que move as relações sociais. O clássico "Ensaio sobre a dádiva" de Marcel Mauss (2003), por outra via, também formula o ciclo da dádiva - "dar-receber-retribuir" - como "liga" do "viver juntos". O mesmo emerge, ainda, da formulação de Nancy (2000) da comunidade enquanto "ser-em-comum", experiência do risco e do enfrentamento recíprocos, como ele diz. Trata-se do risco da exposição ao acidente, diria: o risco implicado na tarefa de manuseamento atento da metaestabilidade entre as doses de saque e dádiva de cada relação, re-mediando-as através de um constante investimento no "aprender a receber", trabalho minucioso de ajuste e sustentação que vai, aos poucos, fazendo com o que o "dar seja já um retribuir, e o retribuir seja ainda um dar". Não se trata de uma conta que se fecha, produzindo "coerência": ao contrário, é de "consistência" por tentativa-e-erro que se trata, pois não há jamais um "suprir da falta”, a não ser sob pena de extinguir a relação. Como evidencia a abordagem de Blanchot (2013) à comunidade, esta não se constitui como instância de "ressarcimento do faltante", mas como lugar de conflito, luta e contestação - se o comum assegura qualquer coisa, é que não haverá jamais "Eu acabado", uma vez que será na oportunidade constante de se ver não reconhecido, mas contestado ou mesmo negado pelo Outro, que o Eu ancora a sua "consciência", um "si-mesmo" sem hipótese de totalização, que vai se clarificando justamente na impossibilidade de "ser em separado". O commoning não se orienta, portanto, pelo aplacamento ou pela resolução, mas pelo desdobrar ilimitado do "problema do juntos" em um sem-número de arranjos contingentes, que vão dando corpo - consistência - a vidas singulares ou "quaisquer".

A singularidade "qualquer" - impessoal, pré-subjetiva, incapturável pela lógica identitária do pertencimento, uma vez que tem em comum com as outras singularidades quaisquer apenas o fato de serem todas diferentes - é justo o modo encontrado por Agamben (1993) para dizer a força motriz daquilo que chama de "comunidade que vem", e que profetiza ao mesmo tempo a urgência e a eventual emergência de formas de vida coletiva sem nome e sem rosto, sem classe e sem partido, sem gênero e sem gosto, na esteira da falência já ostensiva da moderna política representacional, e nas zonas de sombra e fissura abertas pelas mutações contemporâneas do capital. É a liberação da potência de vida da "multidão", na formulação de teóricos como Hardt e Negri (2004): brecha possível, mas que precisa de ser habitada e disparada novamente e a cada vez, desviando sucessivamente e sem fórmulas prontas dos mecanismos de captura capitalistas cada vez mais conexionistas e rizomáticos.

Se o comum tem-se tornado apto, hoje, a aparecer com a sua máxima força de afetação de maneira imanente, é preciso não se esquecer que é porque isto convém ao próprio sistema na sua feição pós-fordista e se coaduna ao contexto biopolítico atual, que encontra no trabalho imaterial a sua nova fonte de riqueza privilegiada. A contemporânea tendência a uma passagem cada vez mais extensiva dos espaços fechados disciplinares aos espaços abertos (mas controlados e rastreados) das sociedades de controle (DELEUZE, 1992) dá-se sobretudo porque as faculdades inventivas tornaram-se commodities. Entretanto, para capturá-las é preciso liberá-las, e aí está a brecha que sinaliza a potência de limiar do momento histórico em que vivemos: inteligência, cognição, memória, inventividade, imaginação, cooperação, colaboração são ao mesmo tempo as capacidades solicitadas pelo mercado competitivo de alta performance e as faculdades que nos permitem engajar no performar coletivo do comum, se as frequentarmos como vias para a afetação recíproca, para a invenção de novas crenças e desejos e para o desenho de novas formas de vida suficientes. Dissemina-se a clareza infinitesimal desta potência inventiva - que é a do "qualquer" e a dos "muitos" - e despontam, um pouco por toda a parte, comunidades temporárias e experimentais, ocupações e ensaios de outros mundos possíveis, experiências de gestão coletiva do (im)próprio coletivo, redes de solidariedade não-identitárias e que vão ligando os precários que somos todos, em elos vivos: eis a strangership a sinalizar os seus múltiplos modos de materialização possível em "zonas autônomas temporárias" (BEY, 2006), "micro-utópicas" (BOURRIAUD, 2009) ou "alterotópicas" (PETCOU; PETRESCU, 2007).

Mas "é preciso estar atento e forte", pois paradoxalmente isto se tem feito acompanhar pelo agravamento dos esquemas conservadores de apreensão das subjetividades. Se vivemos a aparição dessas micro-formas de encontro sustentado a se experimentarem de um modo cada vez mais disseminado e a emergirem justo do desgaste das formas habituais de sustentação dos vínculos sociais, também vivemos o enfraquecimento do comparecimento coletivo nas esferas públicas, o desmonte e a desfuncionalização cada vez mais ostensivos das formas de associação, e, sobretudo, uma nova onda generalizante de recrudescimento dos esquemas ideológicos reconhecíveis. Isto, a que Pélbart (2003) chama de "sequestro do comum", toma corpo em sucessivas manobras de incitação do medo e do ódio, através da disseminação de pseudo-consensos pré-fabricados, espetacularizados e transcendentalizados pelas grandes corporações de mídia e pela encenação política mundial.

A tomada de posição é, assim, cada vez mais limitada a um plano retórico e confinada à adesão veloz a ideias prontas. Estas, defendidas e discutidas num plano meramente opinativo, se reproduzem praticamente em "modo metástase": como "decalques do empírico" (PÉLBART, 2003) cada vez mais distorcidos, formam uma massa rui- 
dosa em que todos falam e ninguém se escuta, e em que se diz cada vez mais o mesmo e para o mesmo, em ilhas e mais ilhas de opinião "pós-fato" impermeabilizadas umas às outras e, sobretudo, ao múltiplo e ao dissonante.

É, por isso mesmo, particularmente crítico e premente não apenas falar ou saber das formulações conceituais acerca do comum e da comunidade, mas encontrar os funcionamentos justos que permitam efetuá-las em tomada de posição consistente e "sem ideias" (EUGENIO; FIADEIRO, 2013), alinhando em ato o fazer do comum ao fazer do "impróprio". E o impróprio não é outra coisa senão o acontecimento que se (des)dobra a partir da sustentação do encontro, espaço-tempo dissensual e situado que está por emergir, a cada vez, não apenas entre o Eu e o Outro, mas a partir da "expropriação" de ambos, que virá a instaurar uma "dissimetria insuperável" (BLANCHOT, 2013) com a qual se poderá fazer o juntos. Como na formulação de Gabriel Tarde (2007), que nas últimas décadas vem sendo redescoberta em todas as suas implicações, e que descreve a sociedade como fenômeno de "possessão recíproca, de formas infinitamente variadas, de todos por cada um". Eis um modo de dizer a sociedade que, se efetivamente praticado, não apenas teria efeitos de maior precisão conceitual se comparada à noção durkheimiana de sociedade como super-indivíduo coercitivo, anterior e exterior às relações, mas, sobretudo, abriria a hipótese de se constituir e habitar uma forma-sociedade já não mais oposta à forma-comunidade, permitindo, simultaneamente, reajustar a definição e o experienciar de ambas - des-reificando uma, des-romantizando a outra.

Como nos alerta Nancy (2000), a comunidade tem sido ativada, no mundo moderno ocidental, sobretudo enquanto ideia: imagem mítica e nostálgica de um passado imaginário no qual o vínculo teria sido genuíno, puro ou originário, caracterizado por uma comunhão integral, ingênua e desinteressada, antes de que a entrada no contrato social nos apartasse definitivamente. Tanto esta nostalgia do que nunca houve, quanto a pretensão de restauração prospectiva desse ideal, além de perigosamente poderem (como já o fizeram) justificar cruzadas puristas ou reforçar fragmentações identitárias, têm-se prestado sobretudo a desviar-nos, tal e qual uma armadilha mental, do desafio ético concreto e cotidiano de fazer "com o que se tem" (e não com o que se gostaria de ter): e o que temos é a disparidade, a desigualdade, a incoerência, o desencontro, a diferença, a distância. A hipótese do comum não foi interrompida pelo surgimento da sociedade, mas, como sublinha Nancy, emerge enquanto possibilidade justamente por nos confrontarmos com ela: a comunidade é aquilo que "pode nos acontecer" justamente por estarmos imersos num socius no qual escancara-se a dissimetria incontornável introduzida pelo Outro, pelos tantos Outros que interrompem, interceptam e desestabilizam o Eu pleno de certezas e supostamente seguro de seus contornos.

Um Outro que "objeta" o sujeito, como formularia Whitehead (1933/1967): se faz obstáculo, acidente, ferida, fissurando a inteireza do sujeito e instaurando a hipótese de um jogo recíproco, no qual sujeito e objeto passam a ser funcionamentos intercambiáveis, ao invés de papéis hierárquicos e pré-determinados. O comum na já mencionada acepção deleuziana ou espinosista de fundo virtual, vitalidade social pré-individual, ilimitada e portanto apta às mais diversas e contingentes individuações - manifesta-se enquanto potência justamente nesta colisão com aquilo "não" somos e "não" temos. Uma colisão que, por isso mesmo, reabre o que podemos "vir a ser e vir a poder". É com a matéria desta vulnerabilidade ao impróprio que poderá se construir o plano de imanência de "uma" comunidade enquanto co-existência de distâncias e contemporaneidade de ritmos: combate diligente e atento da imagem ilusória da comunidade fusional, dando lugar a um franco compartilhamento da separação e à co-operação de singularidades que não se anulam.

Comunidade "idiorrítmica", como na fantasia de Barthes (2003), somente possível se concedermos estar co-munes uns com os outros, expondo-nos e arriscando-nos à contaminação recíproca, mas também experimentando e investigando na prática o que podemos ou não juntos. Jogar, assim, aos undercommons (HARNEY; MOTEN, 2013): "jogo do incompletarmo-nos uns aos outros", no qual o encontro liberta-se do espectro da simbiose ou da miragem do encaixe perfeito, para assumir-se enquanto oportunidade para "multiplicarmos as nuances da nossa própria incompletude". Um jogo que só poderá ser ético, consistindo a ética justamente neste "estudo praticado e situado das possibilidades imanentes de composição". Ou ainda, como a pensou certa vez Foucault (2004), num cuidar de si e do outro num só gesto, dando lugar a uma "prática refletida da liberdade".

\section{"Des-imunização" e corporeidade: a malha vital do encontro}

Talvez se possa dizer que uma das incidências mais cerradas do Modo Operativo É se operacionalize num insistente e reiterado trabalho de "imunização" ao outro, ao entorno, ao Fora. Isto seria apenas uma maneira diversa de dizer como o individualismo, enquanto subjetividade característica dos funcionamentos capitalísticos, se cumpre e faz cumprir a cosmovisão (pós-)moderna, desativando o "co-passionamento" em passionamento narcísico e distorcendo os processos vinculativos espiralados do dar-receber-retribuir em ciclos infinitos e insaciáveis de saque-consumo-descarte.

Se a subjetividade individualista emerge, como já mencionado no início deste texto, como duplo da forma-Estado, será preciso encontrar na prática - e adensar por frequentação comprometida - as muitas zonas de sombra desse funcionamento. São as brechas, territórios intersticiais ou liminares, nos quais o tecido da convivência se faz por conjuração dos mecanismos de Estado, expondo valências "contra o Estado" - no sentido tão bem catalisado na análise de Clastres (1978) sobre as "sociedades primitivas". Passar não só a dizer, mas a viver o mais assiduamente possível um socius que é "têxtil e não texto", vai abrindo caminho para re-materializar uma outra corporeidade e uma outra subjetividade, assentes explicitamente no co-munus: no reconhecimento de que "somos feitos de outros". No reconhecimento, em suma, de que esta coisa 
que chamamos de "Eu" seria muito mais justamente descrita através de um inventário (que só pode ser constante) daquilo que se propaga entre o que fica e o que parte; dos modos e modulações destes atravessamentos; dos sedimentos, restos, rastros, traços e resíduos (com doses, ritmos e durações os mais diversos) que estes deixam ou levam. Não há nada a defender, não há de quem ganhar ou perder; não é de todo possível viver "imune" quando existir é contaminar e ser contaminado. Não vale a pena desistir, mas tampouco resistir, quando existir é "re-existir".

O Modo Operativo AND enquanto prática de "reparagem" - feita de uma tripla modulação: o "re-parar" (voltar a parar), o "reparar" (notar, desfragmentar, fractalizar) e a "reparação" (re-materializar e reabilitar para o uso) - convida justamente a trabalhar no desfazimento da imunização - seja aquela vivida como desistência ou aquela vivida como resistência. Convida a fazer da prática da atenção uma prática de "des-imunização" - de franca sensibilização ao outro, ao acidente, ao encontro, ao imponderável -, criando as condições concretas para a emergência da forma relacional aberta da strangership, a partir do manuseamento situado e consequente do que temos e do que nos têm, do que podemos ou não a cada vez, e de como isto tudo ganha corpo nas nossas tomadas de posição. Explicita-se assim a precariedade e a transitoriedade de qualquer "próprio", no reconhecimento concreto e situado de que este, a emergir, tomará a forma de um plano comum de contornos porosos, circunstanciais e provisórios, comunidade "inoperante" (no sentido atribuído por NANCY, 2000) e por isso mesmo autônoma enquanto durar, associação pronta a dissociar-se, que será sempre consequência - e não causa - da entrada em relação.

Sintonizar com esse funcionamento vital que acontece desenhando e entrelaçando linhas numa malha (INGOLD, 2007) ou numa rede-teia (DELIGNY, 2015), será algo como tocar num plano ao mesmo tempo anterior e posterior àquilo que Deligny denuncia como "projeto pensado". Será algo como ativar diligentemente uma sensibilidade à ecologia das nossas próprias práticas - o que geram e produzem os nossos gestos, e quê gestos efetivamente manifestamos, a despeito das intenções. Transferir o foco, em resumo, das "intenções" para as "inclinações". Frequentar o Fora das redes de certeza e das relações de mesmidade, acionando a confiança como método. Sim, pois as malhas do mundo com estranhos são tecidas "com-fiança".

E depois, desapegar: perdoar (forgive) "para dar" (for give) - ou "retribuir", que não é senão um voltar a dar. E depois, desaprender: esquecer (forget) "para ter" (for get) ao invés de ser; para conseguir "receber". Desorganizar o corpo que sabe e identifica para ir fazendo situada e contingentemente o corpo que saboreia e "co-passiona". "Desertar-se" (DELEUZE, 2006), a fim de atingir o limiar não apenas da potência, mas sobretudo da impotência, daquilo que "podemos não fazer" (AGAMBEN, 2014). Transferir o dizer de si do monólogo aguerrido ou do diálogo relativizante para o "metálogo" (BATESON, 1996): uma disposição para ficar no problema que se apresentar, para sentir-pensar-fazer junto, consuman- do um modo de saber tátil, exploratório, atmosférico e comprometido. Um "modo que faz do saber, sabor". Instauram-se aí as condições para que possamos entrar em contato com uma certa sabedoria da "liminaridade" (como no clássico sentido atribuído por Turner a communitas), a partir da qual reencontrar o "jogo" como espaço de "re-existência" e de invenção vital, resgatando-o do lugar domesticado e estéril no qual foi sucessivamente alocado como lazer regulado ou mero entretenimento. Reativando, aliás, o sentido forte do "entre-ter" enquanto sustentação recíproca - "só temos uns aos outros" - que vai fazendo um meio, o "plano comum".

Perguntar no que consiste a corporeidade "co-passionada”, então, poderá ser ir tornando pensável, sensível e habitável um "corpo desperto na medida em que des-esperto", hábil em não se fixar e fechar em "expertises". Poderá ser, ainda, ir abrindo espaço para uma descolonização não apenas do pensamento, mas da presença. Não o corpo que sabe, mas "um" corpo que "sabe a". "Sabe a" viver só, e por isso consegue viver junto. Corpo fractal e não fragmento: não parte de um código que lhe dê sentido, pauta ou script, mas já ele próprio um mundo, um "inter-isso" nunca inteiriço, em constante "re-perguntar-se". Corpo-envelope, invólucro circunstancial, "zona de transferência" e intercessão de afetos, lugar de enunciação e maquinação de outros mundos possíveis que saltam como consequência da sua "responsabilização". Dizer deste corpo que é responsável é dizer que responde, mas é também re-encontrar o responder na sua dimensão de comparecimento e não de acerto ou solução. Aqui convém afinar com o conceito chinês de gang ying, tal como explicitado por Jullien (2010), que ajuda a perceber a responsabilidade enquanto responsividade, e esta enquanto disponibilidade: constante esvaziar-se de soluções, para que a resposta possa ser re-pergunta, para que o responder possa ser "metadialogar", para que o corpo possa ser o efeito da reciprocidade.

\section{Referências}

AGAMBEN, G. A comunidade que vem. Lisboa: Presença, 1993

AGAMBEN, G. Nudez. Lisboa: Autêntica, 2014.

BARTHES, R. Como viver junto: simulações romanescas de alguns espaços cotidianos. São Paulo: Martins Fontes, 2003.

BATAILLE, G. A experiência interior. São Paulo: Ática, 1992.

BATESON, G. Metadiálogos. Lisboa: Gradiva, 1996.

BEY, H. Zona autônoma temporária. Porto Alegre: Deriva, 2006.

BLANCHOT, M. A comunidade inconfessável. Brasília: UNB, 2013.

BOURRIAUD, N. Estética Relacional. São Paulo: Martins Fontes, 2009.

CLASTRES, P. A sociedade contra o Estado. Rio de Janeiro: Francisco Alves, 1978.

DELEUZE, G. Spinoza: philosophie pratique. Paris: Minuit, 1981. 
DELEUZE, G. Post-scriptum às sociedades de controle. In: 226 . Conversações. Rio de Janeiro: Ed. 34, 1992. p. 219

DELEUZE, G. O que as crianças dizem. In: Clínica. Lisboa: Século XXI, 2000. p. 73-79. Critica e

DELEUZE, G. Causas e razões das ilhas desertas. In: ORLANDI, L. B. L. (Org.). A ilha deserta: e outros textos. Textos e entrevistas (1953-1974). São Paulo: Iluminuras, 2006. p. 17-22.

DELIGNY, F. O aracniano e outros textos. São Paulo: n-1, 2015.

DUENHA, M. L.; EUGENIO, F.; DINGER, A. Entre-modos: um jogo de re-perguntas à volta do Modo Operativo AND. Urdimento Revista de Artes Cênicas, Florianópolis, v. 2, n. 27, p. 96-123, dez. 2016. Cross ${ }^{\text {Ref. }}$

ESPÓSITO, R. Communitas. Buenos Aires: Amorrortu, 2007.

EUGENIO, F. Modus Operandi AND: Interview \& Modus Operandi AND in 10 Positions. In: STEPHENS, A. C.; STOKER, G. A Sick Logic. Sheffield: Site Gallery, 2017.

EUGENIO, F. Manifesto AND: um outro mundo possível, a secalharidade. (Das relações entre a Etnografia Recíproca e a Filosofia do Acontecimento). 2010. Projeto (Pós-Doutorado)Instituto de Ciências Sociais, Universidade de Lisboa, Lisboa: 2010.

EUGENIO, F. Glossário AND. AND Mag, revista electrónica do AND Lab [online], Lisboa, 2012. Revisão e edição de Liliana Coutinho. Disponível em: <https://magazineandlab.wordpress. com/category/glossario-and/>. Acesso em: 20 jun. 2017.

EUGENIO, F.; FIADEIRO, J. Jogo das perguntas: o modo operativo AND e o viver juntos sem ideias. Fractal: Revista de Psicologia, Niterói, v. 25, n. 2, p. 221-246, maio/ago. 2013. Cross $^{\text {Ref. }}$

FOUCAULT, M. A ética do cuidado de si como prática da liberdade. In: MOTTA, M. B. (Org.). Ética, sexualidade e política. Rio de Janeiro: Forense Universitária, 2004. Coleção Ditos \& Escritos, v. 5, p. 264-287.

HARDT, M.; NEGRI, A. Multidão: guerra e democracia na era do império. Rio de Janeiro: Record, 2004.

HARNEY, S.; MOTEN, F. The undercommons: fugitive planning \& Black studies. Nova Iorque: Minor Compositions, 2013.

HORGAN, M. Strangers and Strangership. Journal of Intercultural Studies, v. 33, n. 6, p. 607-622, Dec. 2012. Cross ${ }^{\text {Ref. }}$

INGOLD, T. Lines. London: Routledge, 2007.

INGOLD, T. Trazendo as coisas de volta à vida: emaranhados criativos num mundo de materiais. Horizontes Antropológicos, Porto Alegre, ano 18, n. 37, p. 25-44, jan./jun. 2012. Cross ${ }^{\text {Ref. }}$

JULliEN, F. Um sábio não tem ideia. São Paulo: Martins Fontes, 2000.

JULLIEN, F. De lo universal, de lo uniforme, de lo común y del diálogo entre las culturas. Madrid: Siruela, 2010.

LATOUR, B. Il n'y a pas de monde commum: il fault le composer. Multitudes, v. 45, n. 2, p. 38-41, 2011. Cross ${ }^{\text {Ref. }}$

MAUSS, M. Ensaio sobre a dádiva. In: Sociologia e Antropologia. São Paulo: Cosac Naify: 2003. p. 183-314.
NANCY, J.-L. La comunidad inoperante. Santiago de Chile: Arcis, 2000.

NANCY, J.-L. À escuta. Lisboa: Chão da Feira, 2014.

PÉLBART, P. P. A comunidade dos sem comunidade. In: Vida capital: ensaios de biopolítica. São Paulo: Iluminuras, 2003. p. 28-41.

PETCOU, C.; PETRESCU, D. Acting Spaces: transversal notes, on-the-ground observations and concrete questions for us all. Atelier d'Architecture Autogéreé, Paris, 2007. Disponível em: < http://www.urbantactics.org/documents/ActingSpace-CP\&DP. pdf >. Acesso em: 12 mar. 2017.

RANCIÈRE, J. A partilha do sensível. São Paulo: Ed 34, 2005.

SLOTERDIJK, P. La mobilisation infinie: vers une critique de la cinétique politique. Paris: Christian Bourgois, 2000.

STAVRIDES, S. Common spaces: the city as commons. London: Zed Books, 2016.

TARDE, G. Monadologia e Sociologia e outros ensaios. São Paulo: Cosac Naify, 2007.

VIVEIROS DE CASTRO, E; ARAÚJO, R. B. Romeu e Julieta e a origem do Estado. In: VELHO, G. (Org.). Arte e Sociedade: Ensaios de Sociologia da Arte. Rio de Janeiro: J. Zahar, 1977. p. 130-169.

WHITEHEAD, A. N. Objects and Subjects (1933). In: Adventures of Ideas. Cambridge: Cambridge University Press, 1967.

Recebido em: 5 de abril de 2017 Aceito em: 30 de junho de 2017 